\title{
The Power Transmission Stability and Efficiency of V-belts
}

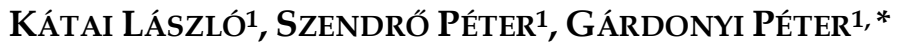

\begin{abstract}
The V-belt drive is a rather popular, widely used form of power transmission in agricultural and food industry engineering. At the same time, its stability, the lifetime of V-belt is influenced by several environmental factors, namely in the food industry by the contamination affecting the belt sides, the ambient temperature, humidity and the occasionally aggressive (acidic, alkaline air, air saturated with gases, etc.) medium. In the case of agricultural machinery, the vibration caused by uncertainly oriented pulleys with bearing in different plate structures (often being shaken in the fields) as well as alignment adjustment inaccuracies jeopardize the reliability of the parameters of the drive. Furthermore, the efficiency is determined by several factors together: the slippage occurring during drive transmission, the hysteresis loss resulting from the external and internal friction occurring with the belt entering and exiting the pulley. Experimental equipment and calculation methods were developed to determine the dynamics of temperature increase generated by the belt and pulley relationship. The temperature generated in the V-belt was measured as a function of pretension, pulley diameter and bending frequency. The so-called damping factor characterizing the contact with the pulley (the external friction when entering and exiting the groove) and the hysteresis loss (inner friction) are also determined. On the basis of the damping factor $\left(\xi \approx 400 \mathrm{Ns} / \mathrm{m}^{2}\right)$ of the Vbelt involved in the experiments the other losses $\left(P_{\text {oth }}\right)$ occurring from the pulley-V-belt contact and internal friction may be estimated. The drive parameters may be optimized with the mathematical model describing the effect of the pulley diameter and belt frequency on the increase in temperature.

A standardized calculation method as well as design factors valid for the properly adjusted drive and normal operating conditions determined through empirical and laboratory experiments are used for the sizing of V-belt drives. The lifetime of V-belt drives designed in this way, used in extreme conditions typical of agricultural machinery will not be appropriate and will not provide clear, predictable information for maintenance planning. In such cases the results of our own many lifetime tests conducted in the given circumstances can be safely relied on.

The agricultural harvesting machines are large plate-body self-propelled structures on which most of the power supply of the (threshing, cleaning, moving, etc.) machine units handling the crop is realized via belt drives. The distance and angular displacement of the axes involved in the drive can vary within wide limits. The misalignment and angular displacement of the pulleys can be the result of installation instability - due to the plate structure - and the deformation of the plate structure occurring during the
\end{abstract}

* Corresponding author. Phone: +36-28-522080, E-mail: gardonyi.peter@gek.szie.hu

1 Institute of Mechanics and Machinery, Faculty of Mechanical Engineering, Szent István University, Páter K. u. 1, H-2100 Gödöllő, Hungary 
operation as well. V-belt drives operate satisfactorily under such conditions as well, however these faults are unfavourable in terms of belt lifetime and result in the reduction of drive efficiency.

A further aim of our research is to examine through experiments the lifetime and efficiency of V-belts used in agricultural machines as a function of drive adjustment errors. According to the results of the measurements of the geometrical adjustment errors of V-belt drives performed in the field, the pulleys of agricultural equipment are not always positioned in the medium plane of the drive. In our experiments these data served as independent variables. Figure 1 shows the arrangement of a V-belt drive in a grain harvester with the laser pulley alignment measuring instrument installed as an accessory. In the case of many machine types in $80 \%$ of the tested drives three times the permissible error was measured, and because of off-road use, due to dynamic load these errors further increased as a result of the frame deformation.

The results of both the belt bending testing and the geometrical adjustment testing of the drive offer great help in the design of belt drives. At the same time they can be the source of lifetime and efficiency forecasts.

Keywords: V-belt, viscoelastic model, belt efficiency, internal friction, external friction, hysteresis loss, infrared thermal analysis, belt misalignment, temperature conditions

\section{Introduction}

V-belt drives are widely used in various industrial and agricultural equipment for power transmission. Power transmission is based on friction which has some advantages and disadvantages. Since the drive element is made from flexible materials, the drive will be flexible and minor load peaks might occur. In case of overload the driven side is protected by slipping. However, friction also means that due to the slip the transmission (i.e. the revolution of the driven equipment) may vary between certain limits, and therefore it can only be used in such areas where this is not a disadvantage.

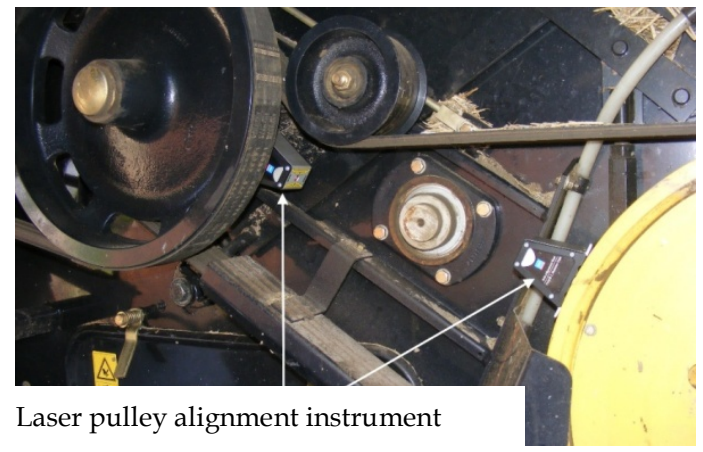

Fig. 1. The arrangement of a V-belt drive in a grain harvester 
One of the significant factors affecting the lifetime of V-belts is the temperature generated within the belt, which is determined by the temperature of the operating environment and by the operating characteristics of the drive.

If the steady operating temperature of the V-belt is tested as loss intensity, the efficiency of the belt drive can be deducted from it [8]. High belt temperature leads to the degradation of polymer molecule chains and as a result to aging of rubber material, which highly influences the V-belt lifetime. V-belt temperature above $70^{\circ} \mathrm{C}$ causes significant decline of expected belt lifetime. In Fig. 2 it can be seen that in case of $10^{\circ} \mathrm{C}$ increase in temperature the lifetime falls to half of its original value. [14].

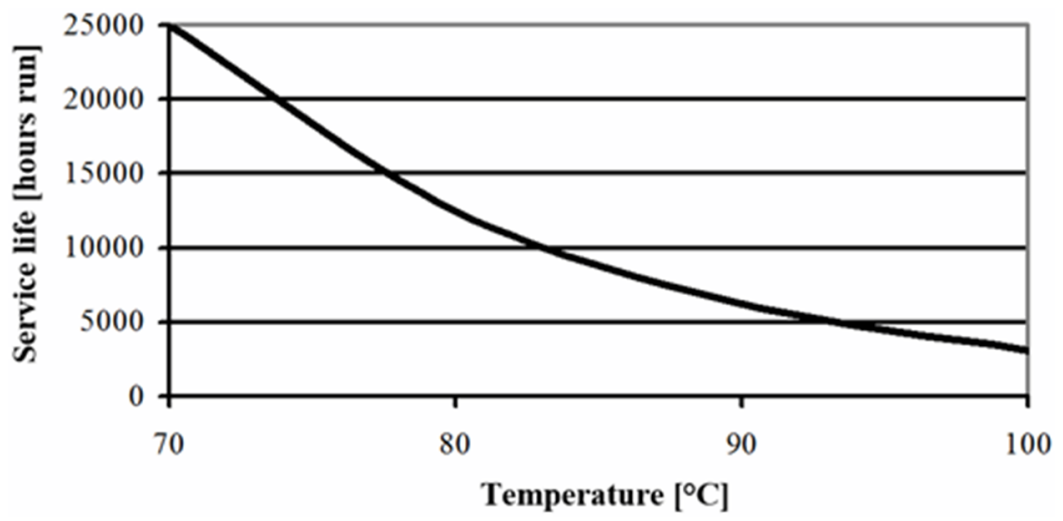

Fig. 2. Correlation between temperature and service life

According to Gerbert [10] the power loss occurring with V-belt drive can be basically divided into two groups, the loss caused by external friction (slip between the belt and the pulley) as well as the loss caused by internal friction (slip among the molecules, hysteresis).

These losses may be further categorized and divided taking into account the operating characteristics of the drive. Another source of loss is the gradual slip that occurs during the operation of the drive. This may be classified as external friction, which is caused by belt creep resulting in the actual slip. The secondary source of loss - which may be classified as external friction - is the slip between the belt and the pulley surface when the belt enters and exits the pulley $[1,2,4,5,21]$. The phenomenon of slip and the effect of drive characteristics on slip are analysed by Gerbert [11] in detail.

Several researchers lay special emphasis on studying slip caused by belt creep. The friction and elasticity of the belt along the angle of wrap is a distinction that can be made between the angular domains of adhesion and 
slippage. This relative displacement occurs between the pulley and the belt, which also leads to heat generation $[6,9,17,19]$. The loss occurring during the entry and exit phase was also studied by Gerbert [10], which shows a larger margin of loss.

The loss resulting from inner friction (hysteresis loss) occurs when the belt is bent on the pulley (bending loss), which undergoes elongation due to the force of the power transmission (loading loss) and is then compressed in the pulley groove (compression loss). The terms in brackets are used by Gervas and Pronin [12]. According to both Gerbert [10] and Gervas [13] the load loss is extremely small. On the basis of the studies by Gerbert, the parameters typical of the tests which were run showed that the loss resulting from compression was smaller by more than one order of magnitude than the bending loss, so its effects were ignored during our study.

Considering the above listed loss components the efficiency of V-belt drive can be expressed in the following way:

where,

$$
\eta=\frac{P_{\text {out }}}{P_{\text {in }}}=\frac{P_{\text {in }}-P_{\text {loss }}}{P_{\text {in }}}=1-\frac{P_{\text {loss }}}{P_{\text {in }}}
$$

$\eta$ - drive efficiency,

$P_{\text {out }}$ - useful (output) power on the driven shaft $[\mathrm{kW}]$,

$P_{\text {in }}$ - input power on the driver shaft $[\mathrm{kW}]$,

$P_{\text {loss }}$ - power loss in the drive $[\mathrm{kW}]$.

Losses can be divided into two categories on the basis of the previously mentioned operating characteristics. Differentiation can be made between slip losses $\left(P_{s}\right)$ and other losses $\left(P_{\text {oth }}\right)$, the latter meaning the loss category resulting from the contact of the V-belt and the pulley, which is the loss of the internal friction due to bending $\left(P_{I}\right)$, as well as the loss due to the external friction of the V-belt entering and exiting the pulley groove $\left(P_{E}\right)$. The loss deriving from the friction between both the belt and the pulley as separate measurements are interpreted by Gervas. The slip resulting from power transmission and the friction occurring when the V-belt enters and exits the pulley groove. Based on all of these observations, the efficiency of the drive can be interpreted as follows:

$$
P_{\text {loss }}=P_{s}+P_{\text {oth }} ; \quad P_{\text {oth }}=P_{E}+P_{I} ; \eta=1-\frac{P_{s}+P_{E}-P_{I}}{P_{\text {in }}} .
$$


Taking into consideration that the power of the drive can be determined by multiplying the peripheral force $\left(F_{t}=F_{1}-F_{2}\right)$ and the belt speed $(v)$ :

$$
\begin{gathered}
\eta=\frac{P_{o u t}}{P_{\text {in }}}=\frac{F_{t d n} \cdot v_{d n}}{F_{t d r} \cdot v_{d r}}=\frac{F_{t d n}}{F_{t d r}} \cdot(1-s)=\kappa \cdot(1-s) \\
s=\frac{v_{d r-} v_{d n}}{v_{d r}}
\end{gathered}
$$

where,

$s$ - belt slip during power transmission (slip),

$d r$ - driving pulley (subscript),

$d n$ - driven pulley (subscript),

$\kappa-$ loss factor.

The $\kappa$ factor included in equation (1.3) can be interpreted as the factor determining the other loss $\left(P_{\text {oth }}\right)$, and the term $(1-s)$ in brackets gives the slip loss.

The engagement of the V-belt and the pulley, the elemental slips (relative motions) are affected by several factors in addition to drive parameters, such as operating conditions, the polluted environment, temperature and relative humidity as well as drive alignment errors, etc. These macroscopic slips cause belt wear and the heat generated by friction affects the steady transfer of power and its efficiency. The friction has an important role as it was studied by Safranyik et. al. [18]. Moon and Wickert [16] studied the radial belt motions in the case of aligning parallel misaligned pulleys and their effect on the stage of belt engagement. Figure 3 presents enlarged images of the bucking, frictional motion of the $\mathrm{V}$-belt in the groove due to misalignment errors.

The maximum tolerances regarding V-belt drive alignment are given by the producers as a function of the pulley diameter. The nature of the occurring error is disregarded. The maximum tolerance may be due to the parallel misalignment of the pulleys (Fig. 4/a) or the angular misalignment (Fig. 4/b) as well. In both cases the straight belt sections undergo extra bending and the sidewalls experience larger friction where running onto and off the pulley. In case of parallel misalignment, the friction increases on both sides, in the case of angular misalignment it is strained more on one side only. Here is the interpretation of a strained and an unstrained side. [7] 


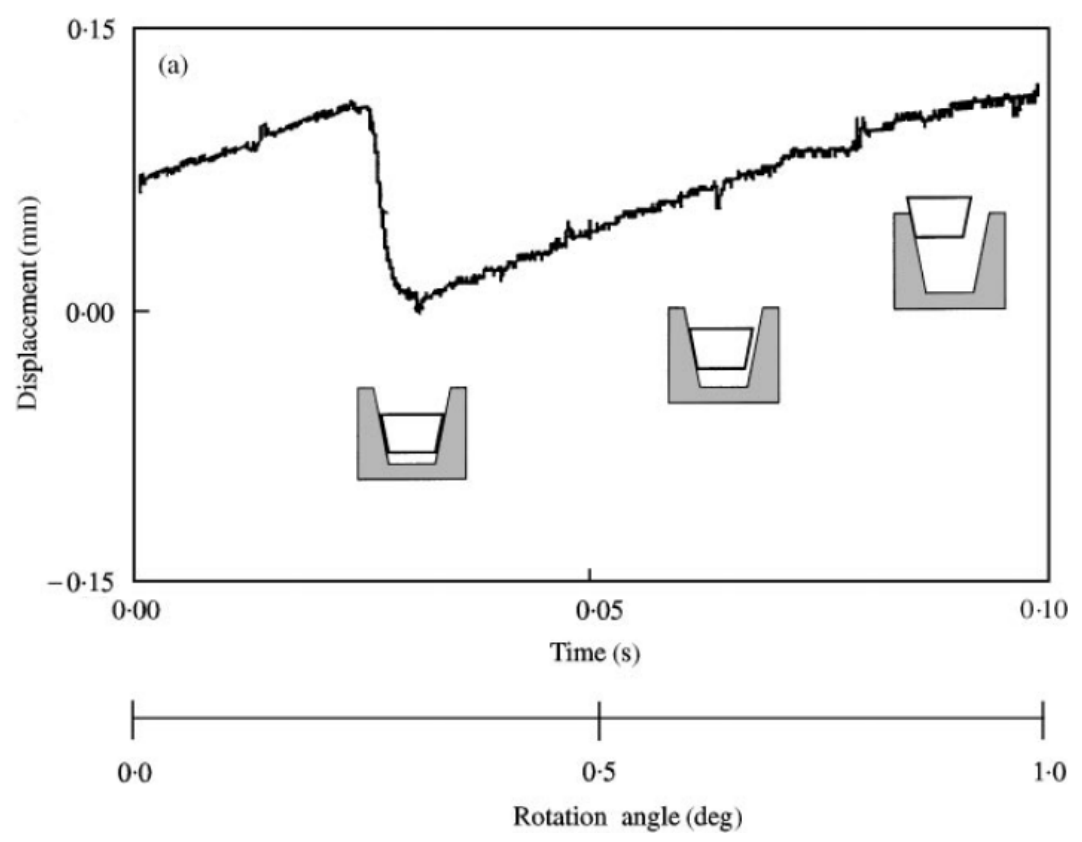

Fig. 3. Stick-slip behaviour of V-belt in the groove
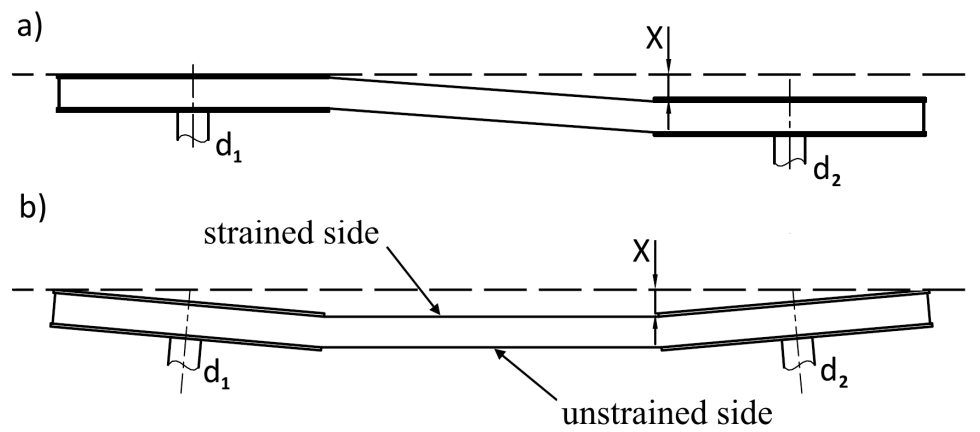

Fig. 4. Explanation the adjustment errors of pulleys

a) parallel misalignment; b) angular misalignment

In this article on the one hand the loss in connection with factor $\kappa$, on the other hand the losses due to the drive installation misalignment are analysed. The increase in temperature occurring as a result of bending combined with the belt entering and exiting the groove is investigated by developing an experimental method of calculation. 


\section{Materials and Methods}

\subsection{Defining the viscoelasticity of $\mathrm{V}$ belts}

Knowing the rheological properties of the V-belt is highly essential for lifetime analysis. One of the factors causing heat generation in the V-belt is the loss occurring during repeated bending, which is created by inner friction. The heat generated during the deformation cycle is subject to the inner friction of the material, the magnitude of the deformation and the speed of the deformation. In case of V-belt drives this means the material of the belt (viscoelastic properties), the diameter of the pulley and the belt frequency.

The V-belt can be treated as a viscoelastic linear model $[3,15,17]$.

The model can be characterized according to Fig. 5 .

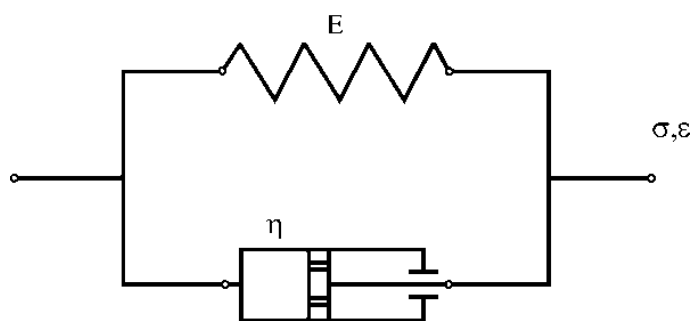

Fig. 5. The material model of the V-belt

The equation of the model in Fig. 5:

$$
\sigma=E \cdot \varepsilon+\eta \frac{d \varepsilon}{d t}
$$

The damping factor marked as $\eta$ is derived from the inner friction of the $V$ belt, and as well as the external friction of the V-belt entering and exiting the pulley.

Introducing the operator $d / d t=s$ to write the equation more simply

$$
\sigma=E \cdot\left(1+s \cdot \eta^{\prime}\right) \cdot \varepsilon=E(s) \cdot \varepsilon,
$$

where,

$E(s)=E\left(1+s \cdot \eta^{\prime}\right)-$ operator elastic modulus, and $\eta^{\prime}=\frac{\eta}{E}$.

One of our aims was to determine the heat produced by the bending process, by observing how the given viscoelastic model behaves during bending strain. 
The bending of a V-belt of $\Delta x$ length can be interpreted according to Fig. 6:
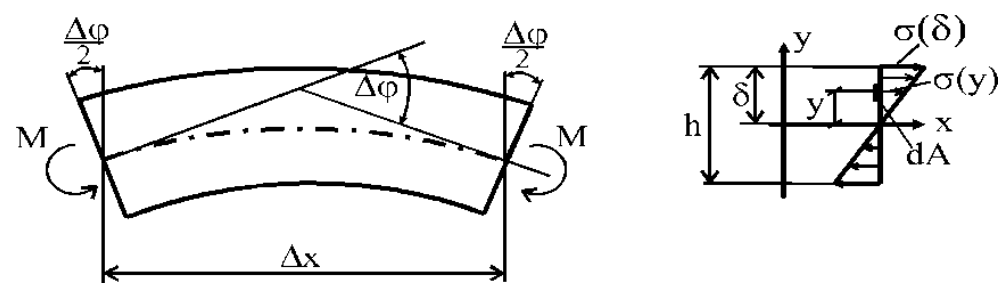

Fig. 6. The interpretation of the bending strain of the V-belt section

It can be assumed that tension and elongation change linearly and accordingly tension is:

$$
\sigma(y)=\sigma(\delta) \cdot \frac{y}{\delta} ; \quad \varepsilon(y)=\frac{\varepsilon(\delta)}{\delta} \cdot y
$$

The angle of rotation according to Fig. 6 is:

$$
\Delta \varphi=\varepsilon(\delta) \cdot \frac{\Delta x}{\delta} .
$$

The bending moment according to equations (2.3) is the following

$$
M=\int_{A} \sigma(y) \cdot y d A=\frac{\sigma(\delta)}{\delta} \int_{A} y^{2} d A=\frac{\sigma(\delta)}{\delta} \cdot K,
$$

where:

- A - the cross-sectional surface of the V-belt [ $\left.\mathrm{mm}^{2}\right]$;

- $K$ - the modulus of section of the V-belt $\left[\mathrm{mm}^{3}\right]$.

The bending moment from the above equations can be written in the following way:

$$
M=\left[E(s) \cdot \frac{K}{\Delta x}\right] \cdot \Delta \varphi
$$

So the V-belt can be interpreted as mechanical resistance, where torque $M$ generates a "flow" equivalent to angular displacement $\Delta \varphi$ according to Fig. 7:

$$
\bar{Z}(s)=E(s) \cdot \frac{K}{\Delta x} .
$$




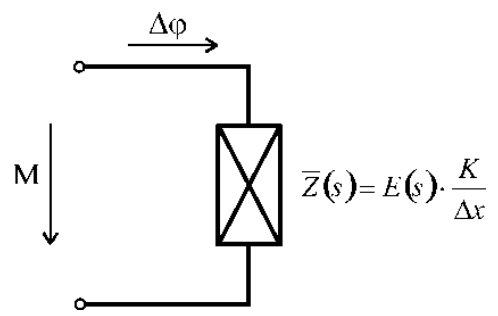

Fig. 7. Interpretation of the V-belt as mechanical resistance

\subsection{Experiment of V-belt bending}

The increase in temperature as a result of bending the V-belt on a test bench designed and built by our research group was tested. The structure of the test bench is shown in Figs 8 and 9.

The tested piece of V-belt was designed for continuous motion by using a steel wire to connect both ends. In order to eliminate the effects of slippage, the V-belt was affixed to the pulley by creating a hole in the belt and securing it to the pulley with a screw. Because of the alternating motion as a result of the angular acceleration/deceleration occurring near the dead points $\left(\varepsilon_{\max } \sim 241 / s^{2}\right)$, and the studied belt section is affected by inertia force. Considering given data for the drive, at its weakest the inertia force hardly reaches $5 \mathrm{~N}$, which does not cause the belt to slip in the pulley. It was possible to pretension the drive made endless as described above by fixing the Bowden pulley around the tilting point with a screw spindle mechanism. With the crank-and-rocker (four-bar) mechanism built in the drive the apparatus generates alternating motion on the driven shaft, thus it bends the pretensioned V-belt on the pulley in the first period of the motion, and then during the opposite motion the V-belt is straightened again. With this motion it is possible to model the deformation of the V-belt occurring during actual drive and to measure the increase in temperature generated by the bending.

The test bench makes it possible to modify several parameters. The revolution of the drive motor can be controlled via a frequency controller, which can be used to alter the bending frequency of the V-belt. The V-belt pulley situated at the end of the drive shaft can be easily modified to alter the pulley diameter used in the test. It is also possible to modify the pretension (the tensioning force affecting the V-belt with the screw spindle mentioned above). 


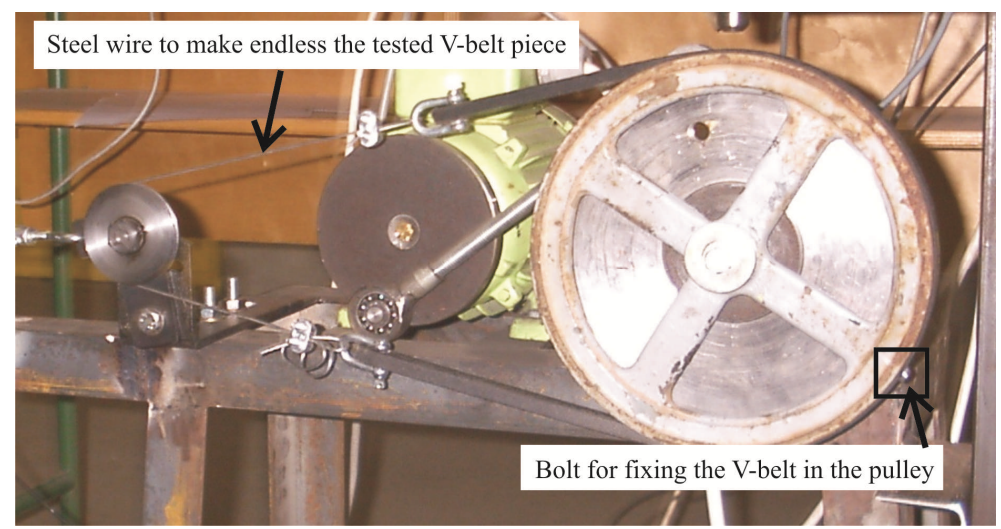

Fig. 8. V-belt displacement on the test bench

The test equipment is shown in Fig. 9.

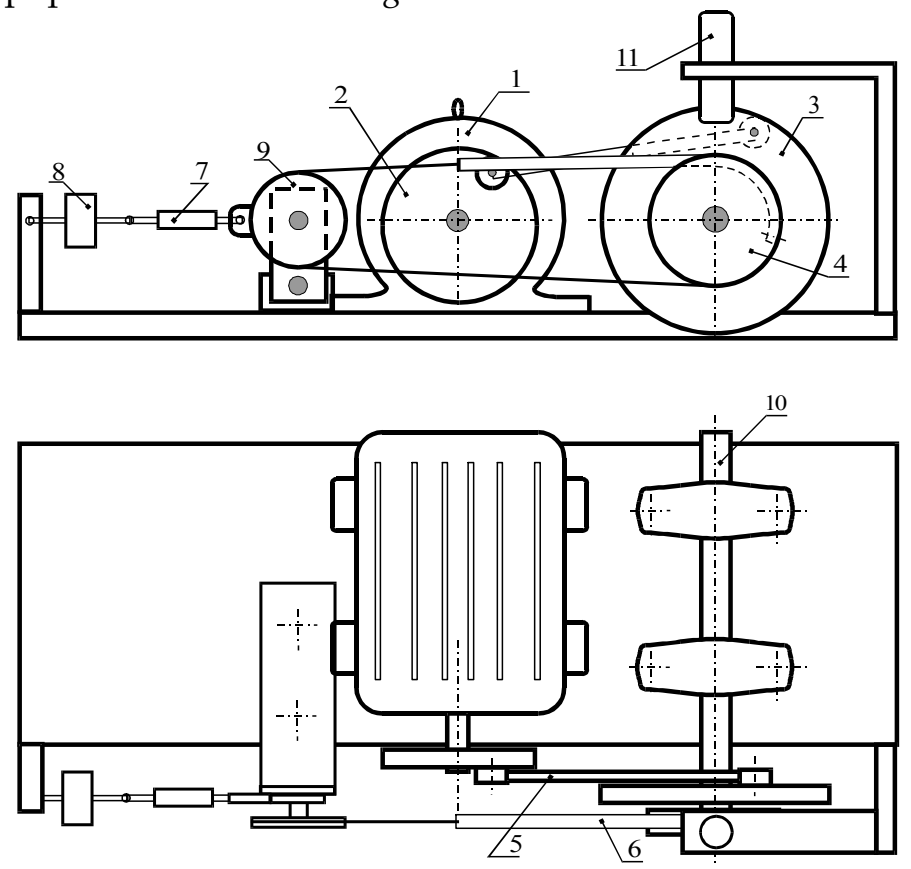

Fig. 9. The drawing of the equipment testing V-belt bending

Note: According to the drawing the test equipment has the following components:

1. drive motor; 2 . drive pulley of four-bar mechanism; 3. driven pulley of four-bar mechanism; 4. V-belt pulley; 5 . drive rod; 6 . tested V-belt; 7. tensioning screw;

8. load cell; 9. Bowden pulley; 10. driven shaft with bearings; 11 . temperature sensor. 
An infrared non-contact temperature sensor was used to measure the temperature. The Impac IN 3000 temperature sensor can be used within the measurement range of $0-120^{\circ} \mathrm{C}$, to an accuracy of $0.1^{\circ} \mathrm{C}$. The temperature sensor was set at $20 \mathrm{~mm}$ from the tested V-belt, which meant that an area of $9 \mathrm{~mm}$ in diameter was sensed, i.e. only the surface of the V-belt.

The measurement results were recorded and processed by an Apple Macintosh computer and the linked measuring amplifier DMC9012A. The measuring software BEAM 3.1 was used with the mentioned configuration, which made it possible to record the data, track the data in real time, and list the required values.

As mentioned above, a three-factor experimental set-up was designed to find out - according to the aims defined in the introduction - how the temperature generated in the V-belt is affected by the frequency of bending, pretension and the diameter of the pulley. On the basis of the measurement results the damping coefficient of the $\mathrm{V}$-belt has been determined, treating it as viscoelastic model. This parameter has influenced the power loss defined in Chapter 1 (Introduction). These parameters are already available in the design phase of the drive so their effect must be taken into consideration. The testing equipment and method are also suitable to evaluate different product developments. With the mentioned equipment, the behaviour of different V-belt cross-section constructions can be determined.

\subsection{Drive installation tests}

The tests were performed on a universal test bench designed by PhD students doing research in the Department of Machine Construction. For the test procedure the drive unit was equipped with a tensioning unit guided by a linear bearing. The pretension of the belt can be adjusted with a screw spindle, whose line of action coincides with that of the shaft pulling force $\left(F_{H}\right)$. This arrangement is used to measure the shaft pulling force directly. The universal test equipment structure can be seen in Fig. 10. During the measurements all the driving parameters can be recorded through a measuring-data collecting unit furthermore to define these parameters with the help of a PLC device.

The temperature of the V-belt is determined by the equilibrium of the generated heat and heat loss. This is affected by several not easily controllable factors, such as air temperature, humidity, the temperature and heat capacity of the contacting parts, etc. During the experiments the mentioned not easily controllable factors were considered constant as the measure- 
ments were taken under the same circumstances. The temperature rise of the V-belt was chosen as the test parameter, which means the power loss between the two equilibrium - between the steady state of the workshop temperature and operating temperature.

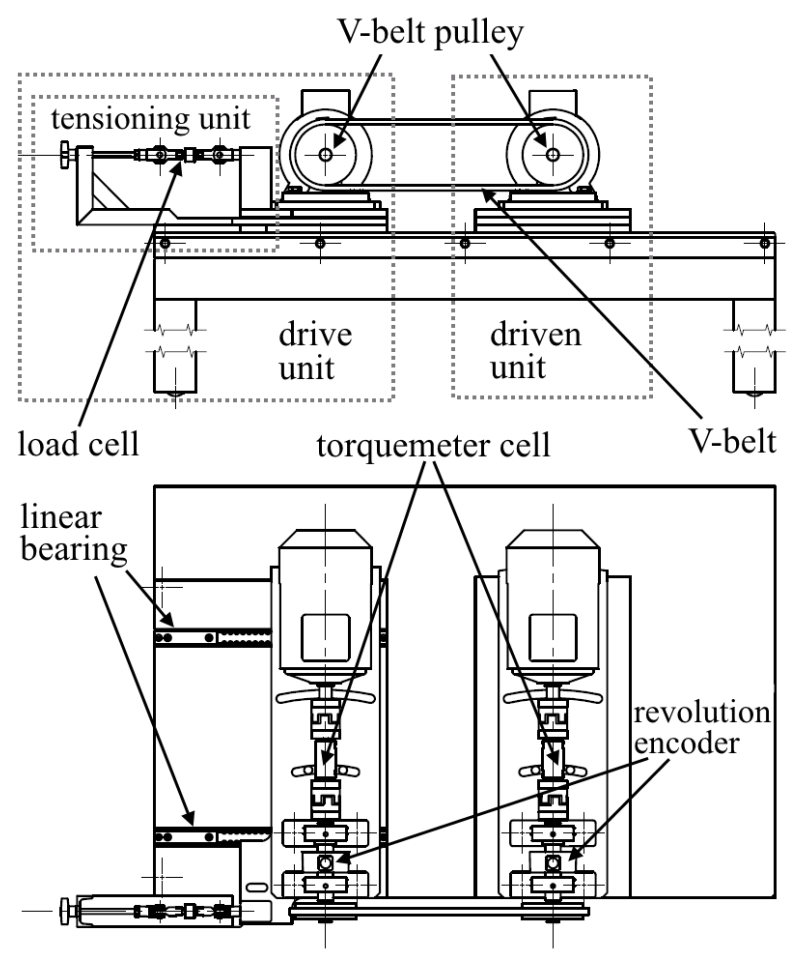

Fig. 10. The structure of the test equipment

During our experiments the sidewalls of the belt coming in contact with the groove were tested, which contained more information about the operation of the drive. Data regarding the temperature were obtained from the thermal images taken of the active surface of the V-belt after the images were processed. We cannot examine the temperature distribution inside the belt section, however, the measurements were done in equilibrium state of temperature (steady surface temperature). There can be a minor temperature difference between the inner and the surface temperature which was neglected. 


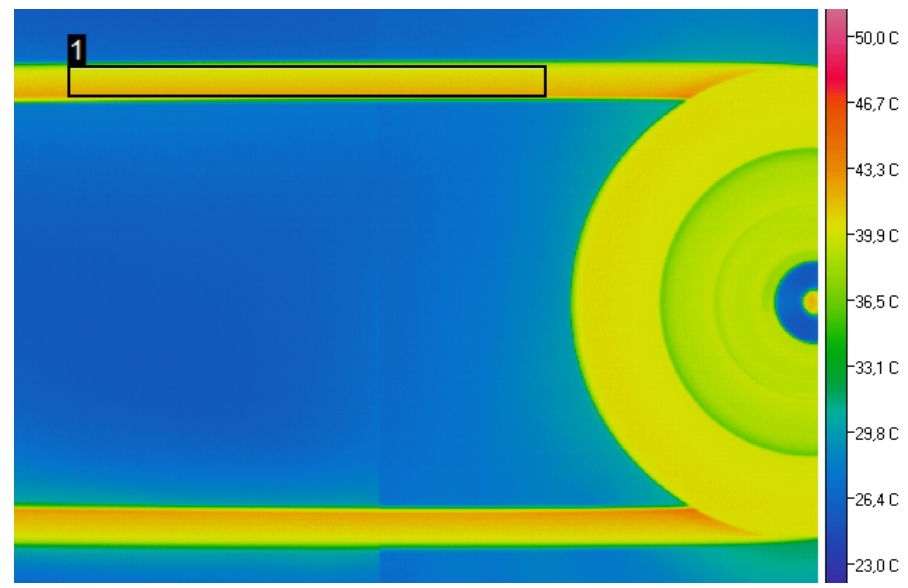

Fig. 11. Thermal camera image and the sampling area

The average temperature of the marked area (1) (Fig. 11) in the tight side was used for the evaluation, which shows the temperature increase of the belt. The warming of the V-belt is described by the Baule-Mitscherlich saturation function (Fig. 12), in which the measured parameters change along a decreasing gradient going toward the saturation maximum [20].

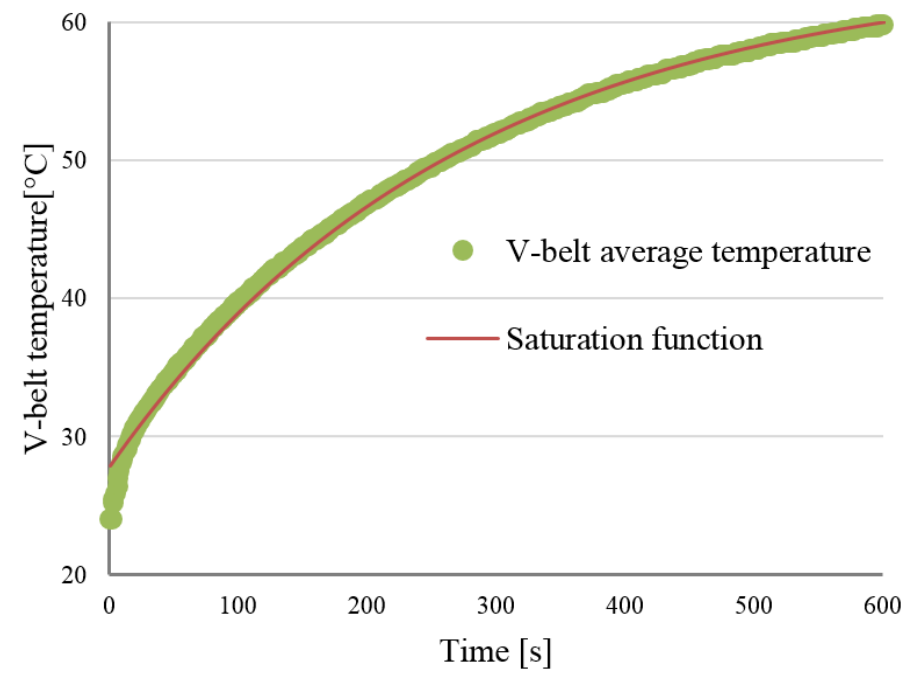

Fig. 12. Measurement data and the saturation function (profil: SPA; $d_{1}=112 \mathrm{~mm} ; i=1 ; L_{d}=1207 ; f_{0}=5.6-23.1 \mathrm{~s}^{-1} ; M_{1}=0 \mathrm{Nm}$ ) 
With the mathematical model it was possible to calculate the steadystate operating temperature, so it did not have to be reached during the experiments. The duration of the measurement was uniformly determined with each experimental setting regardless of whether the belt temperature was steady under the given circumstances or not.

The general equation of the saturation function

$$
Y=A \cdot\left(1+e^{z+c \cdot X}\right) .
$$

The simplified form:

$$
Y=A \cdot(1+m),
$$

where $A$ is the upper limit of the saturation function. The $m=e^{z+c} \cdot X$ is the relative unsaturation.

The fitting of the test data on the saturation function was confirmed by the linear regression of $\log m$. Out of the function parameters $A$ gives the steady-state temperature of the $\mathrm{V}$-belt, $c$ gives the speed of warming and $z$ gives the temperature of the belt at the beginning of the measurement.

\section{Results and Discussion}

\subsection{Modelling of the viscoelasticity of V-belts}

The tests were conducted on the test bench as described in paragraph 2.2 above.

The temperature generated in the V-belt exposed to repeated bending on the test bench is determined by the emerging nominal tension and the frequency of the bending:

$$
\Delta T\left[{ }^{\circ} \mathrm{C}\right]=f(\sigma, f) .
$$

The nominal tension can be set on the equipment by combining the pretension $\left(F_{H}\right)$ and the pulley diameter $\left(d_{p}\right)$, i.e.:

$$
\sigma=f\left(F_{H} ; d_{p}\right) .
$$

The effects of these three factors were investigated. The smallest pulley diameter included in the investigation was selected for the given belt crosssection according to the minimum applicable pulley diameter prescribed by the standard. In the case of the tested section " $\mathrm{A}$ " this meant $d_{p \min }=80 \mathrm{~mm}$. 
The largest pulley tested had a diameter that was $150 \%$ larger than the minimum diameter, i.e. $d_{p \text { max }}=200 \mathrm{~mm}$. This size interval includes the smallest diameters applied in the drives with the given cross-section. The frequency values were selected in the usual range occurring with drives realized in practice $\left(f_{\min }=1601 / \mathrm{min}, f_{\max }=3201 / \mathrm{min}\right)$. The relatively low frequency values are justified by the low revolutions and large belt lengths applied on harvesting machines. Pretension was determined at the medium value of the output range that can be transmitted by the given belt cross-section, and a bottom and top level was determined according to this formula: $F_{H \text { min }}=$ $220 \mathrm{~N}, F_{H \max }=380 \mathrm{~N}$.

When evaluating the results, the increase in temperature was considered the standard since the measurements confirmed that different ambient temperatures (different starting temperature values) the same increase in temperature can be experienced at the given temperature setting. Taking these results into account, the value of the increase in temperature was determined as the difference between the averages of values measured during the first and last 30s:

$$
\Delta T=\frac{\Sigma_{i}^{30} T_{i}}{30}-T_{a m b} .
$$

The parameters set up and measured during the testing are shown in Table 1. The measurements were performed on four different frequency levels and four different pulley diameters, repeated three times. This means $4 \times 4 \times 3=48$ measurements for each pretension value. Since the testing was performed with three different types of pretension, the total number of full experiments including the repetitions was 136.

Table 1. Test parameters

\begin{tabular}{|l|l|}
\hline Input parameters & Measured parameters \\
\hline Motor speed & Pulley shaft RPM \\
\hline Belt pretension & Belt pretension \\
\hline Pulley diameter & Belt temperature \\
\hline
\end{tabular}

The bending of the V-belt section marked as length $\Delta x$ was tested on the test equipment (Fig. 8) described in Section 2.2. The length of the tested section can be calculated with the angular displacement between the dead points defined by the equipment - as a four-bar mechanism, in the knowledge of the diameter of the V-belt pulley. (In its bent state the tested 
section rests on the pulley in its full length, and if it is not bent, the whole tested section is straight). The angular displacement between the dead points on the driven shaft was measured by construction (Fig. 13).

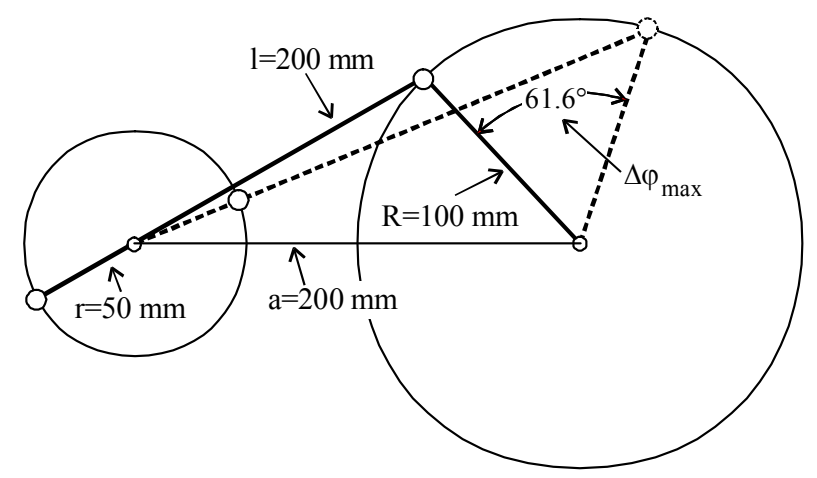

Fig. 13. Measuring the angular displacement between the dead points on the driven shaft by construction

The motion of the V-belt section marked as length $\Delta x$ consists of the following sections: 1. running onto the pulley (the process of bending), and 2 . running off the pulley.

As described above, the repeated bending of the belt section changed the angle $\Delta \varphi$ (Fig. 6) according to Fig. 14.

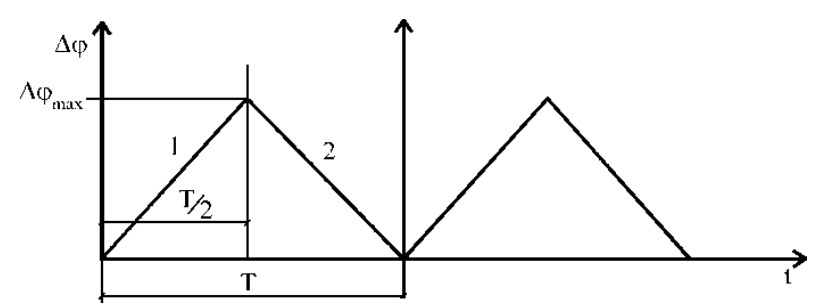

Fig. 14. The change of angle $\Delta \varphi$ as a function of time

If the coordinate axis $\Delta \varphi$ is selected in the middle, an even function is obtained. Therefore when the function is expanded as a Fourier series, cosine terms can be calculated using the formula:

$$
\Delta \varphi(t)=\Delta \varphi_{0}+\sum_{i} \Delta \varphi_{i} \operatorname{cosi} \frac{2 \pi}{T} t=\Delta \varphi_{0}+\sum_{i} \Delta \varphi_{i} \cdot \operatorname{cosi} \cdot \omega t
$$

where, 
$-\Delta \varphi_{i}$ - Fourier coefficients.

The complex amplitude of the torque belonging to each angle amplitude can be calculated in the following way:

$$
\bar{M}_{i}=\Delta \varphi \cdot E\left(1+j i \varphi \eta^{\prime}\right) \cdot \frac{K}{\Delta x}
$$

where,

- $j$ - imaginary unit.

From equation (3.5):

$$
M_{i}=\left|\bar{M}_{i}\right|=\Delta \varphi_{i} E \cdot \frac{K}{\Delta x} \sqrt{1+i^{2} \omega^{2} \eta^{\prime 2}} .
$$

The angle of the complex radius vector:

$$
\operatorname{tg} \alpha_{i}=\frac{i \omega \eta^{\prime}}{1} \rightarrow \alpha_{i}=\operatorname{arctg} i \omega \eta^{\prime}
$$

With this the torque can be determined with the following formula:

$$
M_{i}(t)=M_{i} \cdot \cos \left(i \cdot \omega t+\alpha_{i}\right) .
$$

At the dissipation power:

$$
\begin{aligned}
P_{i}= & \frac{1}{T} \int_{A}^{T} M_{i}(t)=\frac{d}{d t}\left[\Delta \varphi_{i} \cos i \cdot \omega t\right] d t . \\
P_{i}=\frac{1}{2} M_{i} i \omega \cdot \Delta \varphi_{i} \sin \alpha_{i} & =\frac{1}{2}\left(\Delta \varphi_{i}\right)^{2} \cdot E \frac{K}{\Delta x} \sqrt{1+i^{2} \omega^{2} \eta^{\prime 2}(i \omega)} \frac{i \omega \eta^{\prime}}{\sqrt{1+i^{2} \omega^{2} \eta^{\prime 2}}}= \\
& =\frac{1}{2}\left(\Delta \varphi_{i}\right)^{2} \cdot E \frac{K}{\Delta x}\left(i^{2} \omega^{2}\right) \eta^{\prime}
\end{aligned}
$$

Calculating the sum for all the coefficients yields the resulting dissipation power:

$$
P=\sum_{i}=\frac{1}{2} E \frac{K}{\Delta x} \omega^{2} \eta^{\prime} \sum_{i} i^{2} \Delta \varphi_{i}^{2}=\frac{1}{2} \eta \frac{K}{\Delta x} \omega^{2} \sum_{i} i^{2} \Delta \varphi_{i}^{2} .
$$

The warming process can be interpreted by writing the balance of the inner energy in the following way: 


$$
\frac{d U}{d t}=\Phi_{q}+P
$$

where,

- $\Phi_{q}$ - surface heat transfer [J/s];

- $P$ - inner power loss [W].

In stationary state when the temperature of the belt stabilizes:

$$
\frac{d U}{d t}=c \cdot \rho \cdot V \frac{d T}{d t}=0,
$$

where,

- $\quad c$ - specific heat $[\mathrm{J} / \mathrm{kgK}]$;

- $\quad \rho$ - density of the V-belt $\left[\mathrm{kg} / \mathrm{m}^{3}\right]$;

- $\quad V$ - volume of the belt section $\left[\mathrm{m}^{3}\right]$.

It follows from equations (3.11) and (3.12) that:

$$
-\Phi_{q}=P
$$

Assuming that the surface heat transfer can be given as follows:

$$
-\Phi_{q}=\alpha \cdot K_{p e r}\left(T-T_{a m b}\right) \Delta x
$$

where,

- $\alpha$ - surface heat transfer coefficient $\left[\mathrm{J} / \mathrm{m}^{2} \mathrm{~K}\right]$;

- $K_{\text {per }}$ - perimeter of the V-belt [m];

- $T$ - temperature of the V-belt [K];

- $T_{a m b}$ - ambient temperature $[\mathrm{K}]$.

With the dissipation power (3.10) and equation (3.14) the damping coefficient characterizing the inner dissipation of the V-belt can be defined if the heat transfer is considered constant.

Thanks to the measurement results of the bending tests and using the theoretical equations discussed in Section 3, the damping coefficient of the tested V-belt can be defined. This means that it becomes possible to determine the dissipation power for the given $\mathrm{V}$-belt cross section construction, already operating in conditions which differ from the test conditions.

The coefficients of the Fourier series [20] written for the driving function typical of the investigation were defined. The coefficient can be given in the following general form: 


$$
\Delta \varphi_{i}=\frac{4}{T} \cdot \frac{c}{\left(\frac{2 \pi}{T} \cdot i\right)^{2}}(\cos i \cdot \pi-1)
$$

where,

- $\quad c$-gradient of the impulsive function, $c=\frac{2 \cdot \Delta \varphi_{\max }}{T} ;$

- $\quad T$ - periodic time [s];

- $\quad i$ - numbers of Fourier coefficients.

\subsection{Results of bending experiments}

The value of the damping coefficient was defined with data from the series of measurements conducted with $d_{p}=80 \mathrm{~mm}$ pulley diameter. The frequency values set up in the series of measurement were the following: $f_{1}=160 \mathrm{~min}^{-1} ; f_{2}=200 \mathrm{~min}^{-1} ; f_{3}=240 \mathrm{~min}^{-1} ; f_{4}=290 \mathrm{~min}^{-1}$.

With the given pulley diameter the length of the tested belt section:

$$
\Delta x=\frac{d_{p}}{2} \cdot \Delta \varphi_{\max }
$$

The value $\Delta \varphi_{\max }$ is illustrated by the construction in Fig. 13.

From equations (3.11), (3.15) and (3.16) the damping coefficient can be expressed in the following form:

$$
\eta=\frac{2 \cdot \alpha \cdot K_{p e r}\left(T-T_{a m b}\right) \Delta x}{\frac{K}{\Delta x} \omega^{2} \sum_{i=1}^{7} i^{2}\left[\frac{4}{T} \cdot \frac{c}{\left(\frac{2 \pi}{T} \cdot i\right)^{2}}(\cos i \cdot \pi-1)\right]}
$$

The $\kappa$ loss factor written in equation (1.3) according to (3.10) is proportional with the damping factor, $\kappa=C \eta$, where $C$ constant depends on the driving parameters.

According to the test settings (Table 2), calculations made on the basis of the measured results are shown in Table 3. 
Table 2. Test settings data

\begin{tabular}{|l|c|}
\hline \multicolumn{1}{|c|}{ Test parameters } & Values \\
\hline V-belt pulley diameter $\left(d_{p}\right)[\mathrm{mm}]$ & 80 \\
\hline Section modulus of the V-belt $(K)\left[\mathrm{m}^{3}\right]$ & $96.56 \cdot 10^{-9}$ \\
\hline Perimeter of the cross-section $\left(K_{\text {per }}\right)[\mathrm{m}]$ & $37.2 \cdot 10^{-3}$ \\
\hline Maximum angle of rotation $\left(\Delta \varphi_{\max }\right)[\mathrm{rad}]$ & 1,07 \\
\hline Bended belt section length $(\Delta x)[\mathrm{m}]$ & $42.8 \cdot 10^{-3}$ \\
\hline Surface heat transfer coefficient $(\alpha)\left[\mathrm{W} / \mathrm{m}^{2} \mathrm{~K}\right]$ & 10 \\
\hline Ambient temperature $\left(T_{\text {amb }}\right)\left[{ }^{\circ} \mathrm{C}\right]$ & 18.2 \\
\hline
\end{tabular}

Table 3. Results of experiments $\left(d_{p}=80 \mathrm{~mm}\right)$

\begin{tabular}{|l|c|c|c|c|}
\hline \multicolumn{1}{|c|}{ Parameters } & $\begin{array}{c}\text { Frequency } \\
\text { level 1 }\end{array}$ & $\begin{array}{c}\text { Frequency } \\
\text { level 2 }\end{array}$ & $\begin{array}{c}\text { Frequency } \\
\text { level 3 }\end{array}$ & $\begin{array}{c}\text { Frequency } \\
\text { level 4 }\end{array}$ \\
\hline Cyclical frequency: $\omega[1 / \mathrm{s}]$ & 16.75 & 20.94 & 25.13 & 30.37 \\
\hline Cycle time: $T_{c}[\mathrm{~s}]$ & 0.375 & 0.3 & 0.25 & 0.207 \\
\hline $\begin{array}{l}\text { The temperature of the } \\
\text { V-belt: } T\left[{ }^{\circ} \mathrm{C}\right]\end{array}$ & 20 & 20.9 & 22.1 & 24 \\
\hline Damping coefficient $\left[\mathrm{Ns} / \mathrm{m}^{2}\right]$ & 411.98 & 394.86 & 395.64 & 402.73 \\
\hline
\end{tabular}

It can be concluded that the damping coefficient does not depend on the value of the frequency in the tested frequency range, but it can be interpreted as the property of the V-belt cross section and that of the material. The determination of the damping factor for different V-belt types makes it possible to compare other forms of power loss $\left(P_{\text {oth }}\right)$ of the certain types, i.e. to compare efficiency in the case of identical drive parameters.

\subsection{Experiment results of drive adjustment}

First the experiments were conducted with SPA profile V-belts without load. Figure 15 shows that the relationship of the belt frequency and temperature increase is linear in the studied range, i.e. the frequency of the bending strain of the belt is directly proportional to warming. In lower frequency there were no experiments performed, therefore the linear function cannot be extended for wider range of belt frequency. No differences in temperature were experienced between the belt sides and temperature distribution is also uniform along the belt length. 


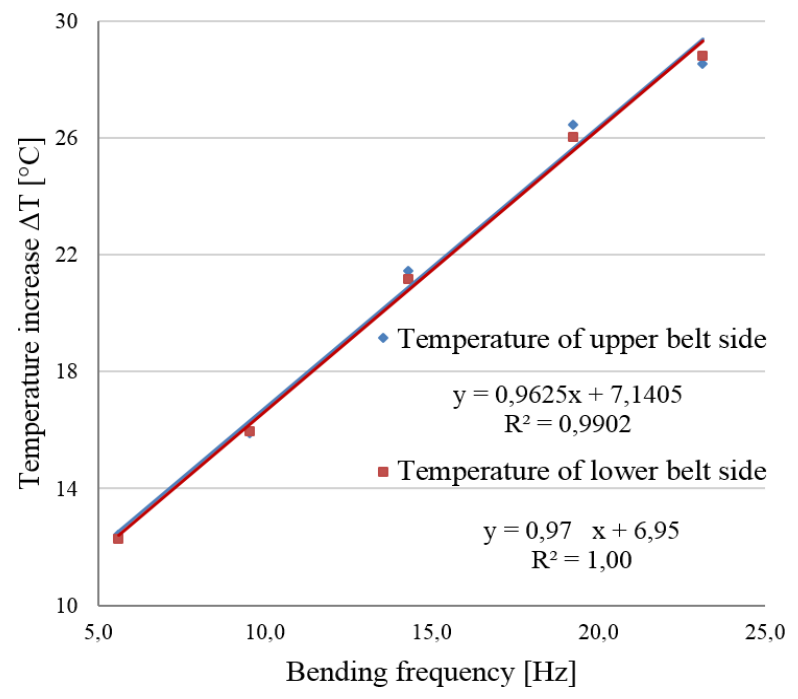

Fig. 15. Temperature increase of the belt sides as a function of the bending frequency (profil: SPA; $d_{1}=112 \mathrm{~mm} ; i=1 ; L_{d}=1207 ; f_{0}=5.6-23.1 \mathrm{~s}^{-1} ; M_{1}=0 \mathrm{Nm}$ )

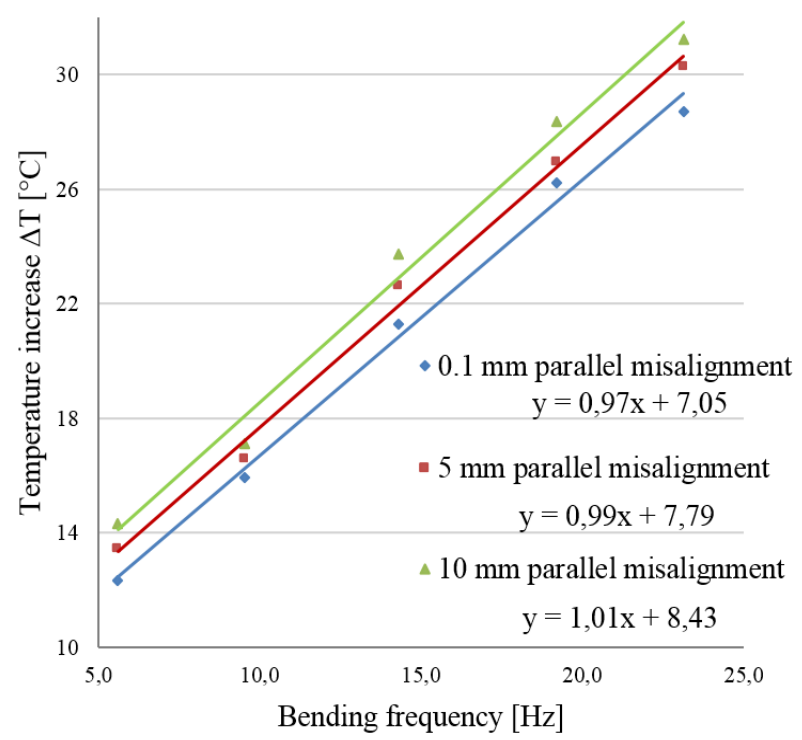

Fig. 16. The heat generated as a consequence of the parallel misalignment of V-belt pulleys as a function of bending frequency

(profil: $S P A ; d_{1}=112 \mathrm{~mm} ; i=1 ; L_{d}=1207 ; f_{0}=5.6-23.1 \mathrm{~s}^{-1} ; M_{1}=0 \mathrm{Nm}$ )

In the case of the parallel misalignment of pulleys, due to the adjustment error the V-belts reached the steady state at a higher temperature 
(Fig. 16), i.e. they worked with higher loss. The parallel misalignment errors of the V-belt pulleys increased the temperature of the belt with a constant value independent of belt frequency, i.e. this excess heat does not come from the inner friction of the material of the V-belt. The heat load generated by the adjustment errors of the pulleys is caused by the changed friction conditions. The largest error set up during the experiments resulted in $10 \%$ temperature increase at each belt bending frequency.

In the other experiments SPZ V-belts were used, where the pulleys were set in the plane of the drive, at the recommended error limit, at a value one order of magnitude larger, and at double that value. The position of the pulleys relative to each other was created with parallel alignment and the angular alignment of the shafts.

Due to the adjustment errors of the pulleys the V-belt drives operate at a higher temperature, thereby the efficiency of the drive becomes worse and the service life of the V-belt decreases. Figure 17 shows that in addition to the extent of the adjustment error the temperature increase of the V-belt is also affected by the nature of the error. The angular misalignment of the pulleys results in different warming on the sidewalls of the belt, which is caused by the previously mentioned different friction influence on the active sidewalls of the V-belt. Heat generation is more intensive on the strained sidewalls, however, the temperature of the unstrained side could be lower than the values within the error limits.

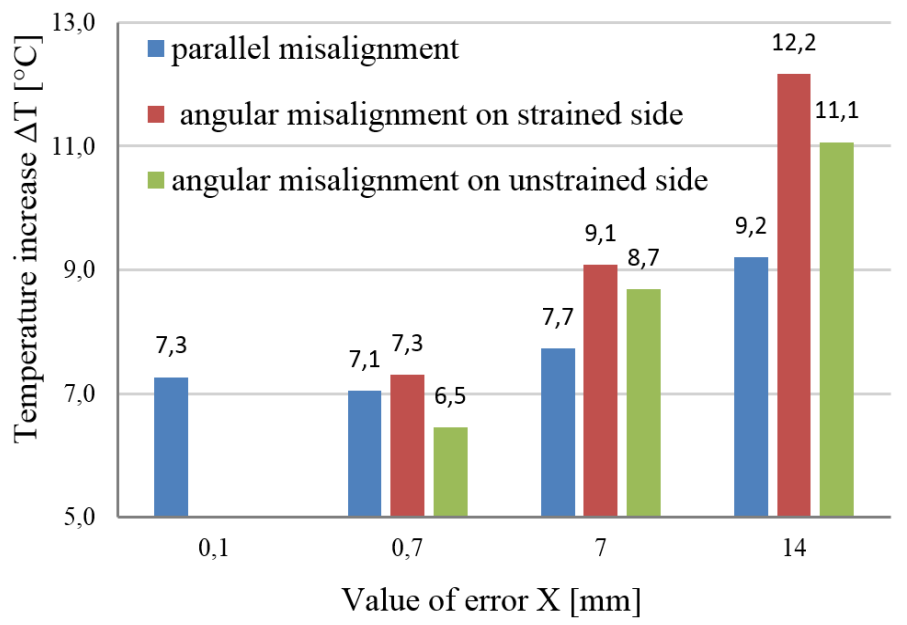

Fig. 17. The temperature increase of the V-belt drive due to geometrical adjustment errors as a function of the extent of the error (profil: SPZ; $d_{1}=150 \mathrm{~mm} ; i=1 ; L_{d}=1207 ; f_{0}=15 \mathrm{~s}^{-1} ; M_{1}=8 \mathrm{Nm} ; F_{H}=119 \mathrm{~N}$ ) 
Within the error limits given by the manufacturers no significant difference can be experienced between the temperature increase of the V-belts. Exceeding the permissible error value the V-belts converge to different temperatures.

\section{Conclusions}

In this article a test apparatus was presented as well as a measurement and calculation method to investigate the heating generated inside V-belts due to repeated bending and engagement/disengagement and to define the damping coefficient during idle running, causing the increase in temperature. Furthermore the drive misalignment effects for the drive efficiency were analysed. The following conclusions can be drawn:

1. It was confirmed by our experiments that the temperature generated in the V-belt cross-section depends on the frequency of the bending, the extent of pretension, as well as the pulley diameter affecting the extent of bending.

2. By treating the V-belt as a viscoelastic linear model an equation was made to define the damping coefficient.

3. The relationship of belt frequency and temperature increase is linear in the studied range.

4. Within the error required by the manufacturers no significant differences can be experienced in temperature increase.

5. The increased frictional conditions play a role in the temperature increase of the V-belt originating from the adjustment errors of the pulleys.

6. In the case of the angular misalignment of shafts the sidewalls of the V-belt - a so called loaded and unloaded sidewall can be defined converge to different temperatures, which are caused by the different frictional conditions of the active sidewalls of the V-belt.

The dominant companies manufacturing industrial and agricultural machines have specific requirements regarding the production of drive components used on their own machines. They would like to increase the reliability of the machines through the unique design of the drive component used for the specific tasks and the unique production of the drive component (V-belt) - even though it is standardized. 
The V-belt bending procedure and the equipment which we have developed as well as the results derived from these could supplement the process of drive development: already in the design phase the temperature expected in the V-belt can be approximated by calculation, which is significant from the point of view of lifetime. In addition, the test results may be used during product development since the bending testing of new cross-section constructions yields important information.

\section{Acknowledgments}

\section{3) SuPPORTED THROUGH THE NeW NATIONAL ExCELlENCE PRO- GRAM OF THE MINISTRY OF HUMAN CAPACITIES}

\section{References}

[1] L. Bertini, L. Carmignani, F. Frendo, Analytical model for the power losses in rubber V-belt continuously variable transmission (CVT), Mechanism and Machine Theory, 78 (2014), pp. 289-306.

[2] H. Belofsky, On the theory of power transmission by V-belts, Wear, 39 (1976), pp. 263275.

[3] C G. Cepon, L. Manin, M. Boltezar, Introduction of damping into the flexible multibody belt-drive model: A numerical and experimental investigation, Journal of Sound and Vibration, 324 (2009), 283-296.

[4] T.F. Chen, D.W. Lee, C.K. Sung, An experimental study on transmission efficiency of a rubber V-Belt CVT, Mechanism and Machine Theory, 33 (1998), pp. 351-363.

[5] T.F. Chen, C.K. Sung, Design considerations for improving transmission efficiency of the rubber V-belt CVT, Int. J. of Vehicle Design, 24 (2000), pp. 320-333.

[6] W.D. Erickson (1987), Belt selection and application for engineers, Marcel Dekker, ISBN 0-8247-7353-5

[7] P. Gárdonyi, L. Kátai, I. Szabó, A hajtás beállítási hiba és az ékszijak melegedési viszonyainak kapcsolata, A Gépipari Tudományos Egyesület Müszaki Folyóirata, LXV (2014), pp. 151-154.

[8] P. Gárdonyi, L. Kátai, I. Szabó, Az ékszijtárcsa átmérők és az ékszíjak melegedési viszonyainak kapcsolata, Fiatal Müszakiak Tudományos ülésszaka, XX, (2015), pp. 26-29.

[9] B.G. Gerbert, Force and slip behaviour in V-belt drives, Acta Polytechnica Scandinavica. Mechanical Engineering Series, 67, (1972).

[10] B.G. Gerbert, Power loss and optimum tensioning of V-belt drives, Journal of Engineering Industry Trans. ASME, 96 (1974), pp. 877-885.

[11] B.G. Gerbert, Belt slip - a unified approach, Journal of Mech. Des., 118 (1996), pp. 432 438. 
[12] K.J. Gervas, and B.A. Pronin, Calculation of power losses in belt drives, Russian Engineering Journal, 47 (1967), p. 26.

[13] K.J. Gervas, Determining the power losses in V-belt drives during flexure, Soviet Rubber Technology, 28 (1969), p. 42.

[14] L. Kátai, I. Szabó, P. Gárdonyi, Az ékszíjak melegedés viszonyainak vizsgálata, A Gépipari Tudományos Egyesület Müszaki Folyóirata, LXIV (2013), pp. 58-61.

[15] L. Mani, G. Michon, D. Remond, R. Dufour, From transmission error measurement to pulley-belt slip determination in serpentine belt drives: Influence of tensioner and belt characteristics, Mechanism and Machine Theory 44 (2009), pp. 813-821.

[16] J. Moon, J.A. Wickert, (1999), Radial boundary vibration of misaligned v-belt drives, Journal of Sound and vibration, 225 (1999), pp. 527-541.

[17] L.D. Pietra, F. Timpone, Tension in a flat belt transmission: Experimental investigation, Mechanism and Machine Theory, 70 (2013), pp. 129-156.

[18] F. Safranyik, A. Csatár, A. Varga (2015), Experimental method for examination of state dependent friction, Progress in Agricultural Sciences, 11 (2015), pp. 29-49.

[19] F.H. Schafer (2007), Antriebsriemen. Arntz Optibelt Gruppe Höxter, ISBN 978-3-000217113-5.

[20] J. Sváb (1973), Biometriai módszerek a kutatásban, Mezőgazdasági Kiadó, Budapest, pp. 390-397.

[21] C. Zhu, H. Kiu, J.Tian, Q. Xiao, X. Du, Experimental investigation on the efficiency of the pulley-drive CVT, International Journal of Automotive Technology, 11 (2014), pp. 257261. 